\title{
Personality and Second Language Learning
}

\author{
Alastair Sharp \\ English Department, Lingnan University, Tuen Mun, Hong Kong, China \\ E-mail: alastair@ln.edu.hk
}

\begin{abstract}
This paper examines the relationships which exist between personality and second language learning and adds to the data available on the use of a highly respected personality indicator, the Myers Briggs Type Indicator (MBTI). Language learning and academic success are both highly correlated with intelligence, but research suggests that the importance of intelligence declines after high school age, partly because of the stronger effects of personality. This study places emphasis on the importance of personality in learning success and examines research evidence on the issue, discussing some of the inconsistent results that have been obtained. A study of 100 Hong Kong university undergraduates was carried out to add to this research base. The instruments used were the MBTI for personality traits, the Strategy Inventory for Language Learning (S.I.L.L.) for learning strategies and a standardized test for language proficiency. Significant statistical relationships were not found and the reasons for this are discussed.
\end{abstract}

Keywords: Personality, Second language learning, Intelligence, Hong Kong

\section{Introduction}

The relationship between personality and second language learning ability, has received some research interest in the last few decades. The results that are available however, have sometimes been inconsistent, often because of methodological and conceptual differences in the way the studies were performed. This article will consider some of the research evidence which has examined these relationships and details a recent study of undergraduate students in Hong Kong which aimed to determine not only the connections between personality, language learning and learning strategies, but also to add to the available data on the personality profiles of Chinese students.

The study will first briefly clarify what might be meant by the terms intelligence, learning strategies and personality, before presenting details of the Hong Kong data collection.

\section{Theoretical Perspectives}

According to Chamorro-Premuzic and Furnham, (2005, p. 40) researchers in cognitive psychology agree on a definition of intelligence which states that it......

“....is a very general mental capacity that, among other things, involves the ability to reason, plan, solve problems, think abstractly, comprehend complex ideas, learn quickly and learn from experience.... it reflects a broader and deeper capability for comprehending our surroundings- 'catching on' 'making sense' of things, or 'figuring out' what to do...."

Many of the elements in the definition of intelligence given above have also been described as indications of the 'good language learner' and have been tabulated in lists of learning strategies that such learners use (Oxford, 1995). Learning a second language successfully requires using reasoning and problem solving abilities and it requires the ability to use and apply strategies which try to make sense of the structure and use of a new language, a clear overlap with definitions of intelligence. Strong elements of successful language learning have been the use of what are called cognitive strategies (the direct processing of language, e.g. memorizing, inferring meaning, solving problems, identifying or making sense of relationships) and metacognitive strategies (thinking about those processes). Both of these have been identified as of crucial importance in strategy research. (O'Malley, et al. 1985a). Attempts have been made to teach strategies for language learning, but these have not met with much success (Hassall, 1984, O'Malley, et al. 1985b). Among the reasons for this may be the fact that the ability to use strategies is related to general intelligence and thus subject to the same developmental, social and genetic influences which limit the effects of direct teaching.

Research has provided evidence of the power of general intelligence in predicting academic performance, including second language learning success (academic performance being estimated by written or oral examinations, continuous assessment, group work, essays or dissertations). (Gagne \& St Pere, 2001, Neisser, et al. 1996, Sternberg \& Kaufman, 1996). However, there is also evidence that general intelligence (as measured by IQ tests) is often not highly correlated with academic performance. (Singh, \& Varma, 1995). Ackerman (1994) and Jensen (1980) report a 
declining correlation as subjects moved from elementary to university education. If intellectual ability, as measured by psychometric tests, has a declining predictive power in adults, the question arises as to what accounts for the difference? It may well be that personality plays a strong role. In other words, general intelligence may be able to predict what a person can do whereas personality type may predict what a person is likely to do. There may well be a strong argument for a greater role to be given to the concept of personality in learning, over the effects of general intelligence.

The next section will look at how we might define personality and what research evidence currently exists to demonstrate its influence on learning in general, and language learning in particular.

\section{Personality}

Personality theory assumes that everyone is different and that individuals are characterized by a unique and basically unchanging pattern of traits, dispositions or temperaments. Personality has however, been studied in a variety of different ways. It has been viewed as pertaining to different forms of information processing styles or learning styles (Messick, 1994). Marton \& Saljo (1976), identified two learning styles: surface-level, characterized by students who memorize and rote learn, as opposed to those who learn at a deeper level. Biggs (1987), in Hong Kong, noted three styles, labeling them as utilizing, achieving and internalizing. There has been also been a view that personality consists of a multitude of specific traits and it is therefore impossible to offer an accurate profile. Examples of traits or dispositions have been: anxiety, locus of control, achievement orientation, intrinsic motivation, self esteem, social competence etc. Multi-trait models have been developed using factor analysis to reduce the wide list of traits to a smaller number of fundamental constructs of personality and which are able to offer more accurate profiles. Multi-trait models have been widely accepted as providing the core features of personality and extensive investigation has demonstrated high levels of reliability and validity. The three best known are the Eysenck Personality Questionnaire, (EPQ) (Eysenck, 1975), the Myers Briggs Type Indicator, MBTI (Briggs Myers, et al., 1998) and the Five Factor Model, (FFM) (Costa and McCrae, 1992). (Appendix 1 summarizes the main features of MBTI with related FFM traits. For reasons of space EPQ is not summarized here.)

\subsection{Multi-trait models and learning}

The research detailed below relates particularly to the personality traits found in the multi-trait models. Such research is cited as evidence that many studies have found a relationship between personality and learning, although not always a consistent one.

Neuroticism (an EPQ trait) has been found to have a clear relationship with general language learning aptitude (Robinson, et al, 1994) and has often been negatively correlated with academic performance (Lathey, 199; Weiss, 1998). It is not surprising that stress and anxiety may affect success in exams, or that Neuroticism may cause a more general effect in terms of attendance, poor health, worry and poor study habits (Woodrow, 2006). Language learning has often been observed as stressful and so such effects would clearly be in evidence. Eysenck \& Cookson, (1969) found that the correlation between Extroversion and achievement changed from a positive to a negative correlation around the ages of 13-14. It is now generally accepted that Introverts (EPQ, FFM and MBTI traits) have an advantage in learning and are more likely to have better study habits (Goh \& Moore, 1987; Sanchez-Marin, et al. 2001), although contradictions remain. In reviewing nine studies connected with second language learning, Kiany (1998) found that two detected a positive relationship with Extroversion and L2 success, three found a positive relationship with Introversion and L2 success, and three found no link. Others point to evidence that Extroverted students learn foreign languages better because of their willingness to interact with others and because of their reduced inhibitions (Ehrman \& Oxford, 1990).

It has also been reported that Psychoticism (an EPQ trait) is negatively related to academic performance. As Psychoticism relates to insensitivity, solitariness and an uncaring attitude, and as such a trait is more likely to be negatively associated with educational settings, this result is unsurprising. Conscientiousness (a FFM trait) is positively related to achievement (not surprisingly) (Goh \& Moore, 1987; Busato, et al. 2000; Blickle, 1996 \& Costa \& McCrae, 1992). Openness/Intuition (FFM and MBTI traits) have been positively associated with academic performance. (Blickle, 1996; Geisler-Brenstein \& Schmeck, 1996). Ackerman (1999) found that a wide vocabulary was associated with Openness/ Intuition. Blickle (1996) suggested that Openness/Intuition were correlated with the desire to use wider learning strategies and learning techniques.

Some relationships have also been found between language teaching methodological issues and personality preferences. (The following evidence refers to MBTI data). Those with a Thinking preference, rather than a Feeling preference were found to prefer more analysis of language data and have a greater ability to see details rather than the global picture. Those with a Feeling preference saw things more globally and sought holistic strategies such as guessing, predicting and paraphrasing, with avoidance of grammatical analysis. Judgers needed more direction and clear grammar rules. Intuitive students were more likely to use abstract principles of language in a more divergent way and feel relaxed with guessing, predicting and other "compensation" strategies. (Sharp, 2005). 
An interesting connection can be made here with discussions on investment theory (Cattell, 1987). This theory posits that certain personality traits related to curiosity, imagination, creativity, intuition and achievement motivation are likely to drive an individual to invest in the development of skills and knowledge. Openness/ Intuition, as aspects of personality, might drive individuals to invest in improved reasoning, problem solving skills, skills in comprehending complex ideas etc, which are clear features of intelligence. This again suggests that certain personality features are related to learning success and to intelligence.

\section{The Hong Kong Study}

A study was carried out with 100 undergraduates at a university in Hong Kong. The purpose of the study was to investigate personality differences (using the MBTI) and strategy use (using the Strategy Inventory for Language Learning, SILL) to see if there were any identifiable relationships between these variables and the students' language proficiency (assessed with a standardized English language test). The study also aimed to present data to add to that already available concerning personality typing in Chinese settings.

Participants:

$$
\mathrm{N}=100
$$

84 female $\quad 16$ male

Mean age $=24.4 \mathrm{yrs}$.

All subjects were ethnic Chinese undergraduates, studying for a degree in English language and literature.

4.1 The selection of MBTI as a research tool

The Myers Briggs Type Indicator (MBTI) was selected as a research tool for a number of reasons:

a) More than 2 million assessments are done each year using this inventory

b) The MBTI has been researched for 40 years, with reliability and validity studies supporting it in a variety of cultures (see Briggs Myers, et al. 1998).

c) The MBTI has a clear and direct relevance to learning. Unlike the EPQ none of the preferences indicated in MBTI have negative connotations (for example EPQ's use of Psychoticism as a trait suggests a tendency towards instability, Neuroticism has similar negative connotations. MBTI traits offer more neutral trait descriptions).

MBTI is made up 4 bipolar scales as shown in appendix 1. Each of the four dimensions is independent of the other three, so the bi-polar scales can be combined to yield 16 possible combinations, ISTJ, ESTJ, ISFJ, ESFJ etc. These 16 combinations are used when presenting the results of MBTI assessments.

\subsection{Learning Strategies}

The Strategy Inventory for Language Learning (SILL) was selected for this study because it has been used frequently around the world in recent years (Oxford, 1995) and therefore allows easy comparison with other studies. It is designed specifically for second language English learners and was therefore appropriate for the subjects in this study.

Strategy use was assessed using a 68 item self-report questionnaire. A Likert scale is used, with sections categorized as follows:

Section A Remembering effectively (memory)

Section B Using mental processes (cognitive)

Section C Compensating for missing knowledge (compensation)

Section D Organizing and evaluating (metacognitive)

Section E Managing emotions (affective)

Section F Learning with others (social)

\subsection{Administration of MBTI and SILL}

The MBTI data collection took 2 hours, attendance was voluntary and great care was taken to explain that the MBTI was not a test and that there were no right or wrong answers. MBTI form $\mathrm{G}$ was used.

The SILL questionnaire was administered in a later session with the students. Both MBTI and SILL results were discussed with the students and it was pointed out how an understanding of personality type and strategy use could be beneficial for students' development and learning.

\subsection{Proficiency Testing}

All students were given a standardized English language proficiency test with multiple choice format, cloze design and open-ended questions to test grammar and reading comprehension. A composite score for both grammar and reading 
is given as a percentage in the next section. It was unfortunately not possible to broaden the type of assessment given to include speaking and listening skills because of time constraints related to student availability at the university where the data collection took place.

\section{Results of Study}

The MBTI results are given below in table 1 and 2. Types are presented as separate traits (table 2) and as 16 alternative combinations (table 1). Tables 3 shows the proficiency results and table 4 the SILL results. Table 5 shows the relationship between MBTI and second language proficiency.

MBTI : key

$$
\begin{array}{llcc}
\text { E - Extroversion } & \text { T - Thinking } & \text { I - Introversion } & \text { F - Feeling } \\
\text { S - Sensing } & \text { J - Judging } & \text { N - Intuition } & \mathrm{P} \text { - Perceiving }
\end{array}
$$

Insert Table 1 and Table 2 here:

Table 1 and 2 show a wide distribution of personality types in the group assessed, as would be expected. The most pronounced are ISTJ, ISFJ and ISFP (table 1). There is a strong preference for Sensing (S) over Intuition $(\mathrm{N})$, Introversion (I) over Extroversion (E), and for Feeling (F) over Thinking (T) (table 2).

Insert table 3 here

Mean score is 70.2. SD 10.3

Table 3 show the composite, percentage scores for grammar and reading comprehension.

Insert table 4 here

\subsection{Analysis}

Some preliminary analysis to investigate the relationships between the variables of personality, strategy use and proficiency is given below.

MBTI and Strategy Use (measured by SILL), with MBTI as the dependent variable, strategy use as the independent variable.

No significant relationships were found, except as given below:

Introversion negatively related to use of SILL social category: $p<=0.011$

Introversion positively related to metacognitive strategy use: $\mathrm{p}<=0.057$

\section{SILL and Proficiency}

No significant relationship was found between SILL categories and proficiency.

Insert table 5 here:

These results indicate no significant relationship between personality and proficiency scores, although there is a slightly higher score related to Introverted students.

\section{Discussion}

This study failed to find any simple direct relationship between personality, learning strategies and second language proficiency. Some studies have found difference in language learning success related to personality (as noted in section 3 above) and teachers continue to regard personality as of considerable importance in learning (e.g. Blease, 1986; Griffith, 1991). However, there have been other studies which have also failed to find relationships. Carrell, et al. (1996), Ehrman and Oxford, (1995) and Carrell \& Anderson (1994) for example, failed to find any direct, simple relationships in their research on the issue. Why then, does the current study, like some others, have such difficulty in establishing relationships between these variables? One reason may be that personality preferences, as set out in the MBTI, give no indication of student maturity, motivation, or of situational factors (a point also noted by Carrell, et al., 1996). MBTI, as mentioned earlier, has very high reliability and validity ratings (Briggs Myers, et al. 1998), but there have been detractors: Zemke (1993) found that MBTI reliability only reached 61\% and Wiggins (1989) put reliability at no more than $50 \%$. A further confounding factor in the present study may be that there was only limited variability in proficiency scores or strategy use. Low variation will obviously result in low correlations. Although a standardized university language test was used, it related only to grammar and reading comprehension. A more comprehensive measure covering listening and speaking skills may have revealed stronger relationships, but as noted earlier this had not been possible in the present study.

Although it has not been possible in this study to demonstrate any clear relationships between SILL, MBTI and proficiency, other studies have sometimes found that successful language learners are more likely to use certain learning strategies (McDonough, 1986; Skehan, 199; Harris \& Grenfell, 2004; Li Qin, 2006). The results of this study show that 
the Hong Kong undergraduates surveyed are in the medium range of strategy usage, according to Oxford (1995). This is also similar to other studies using Chinese subjects (Klassen, 1994; Yang, 1994). The rank order of SILL means is similar to that of the Brenmer (1999) study in Hong Kong (which also used Chinese undergraduates) and to the ranking found by Goh \& Foong (1997) with Chinese students in Singapore. The reasons why there might be this consistency in strategy use amongst Chinese students is certainly worth further investigation in future research on this issue.

\subsection{MBTI in Chinese Contexts}

The results presented in this study only offer a very small sample of MBTI personality preferences in Chinese contexts. Indeed, studies using MBTI in Chinese cultures generally have so far been small in number. Those that are available are referred to below to enable comparison with the current study. Huang \& Huang (1992) assessed university students $(\mathrm{n}=280)$, Yao (1993) looked at school administrators $(\mathrm{n}=293)$ and Broer \& McCarly (1999) management students $(\mathrm{n}=119)$. More recently Li \& Qin (2003) assessed non-English sophomores in two Chinese universities $(\mathrm{n}=187)$. All four studies found that a large percentage of Chinese subjects preferred Sensing. This result is replicated in this study for Hong Kong Chinese students. Sensing may be preferred because it relates to the strategy of memorizing facts and details (a strength of sensing). These are required for success in school exams and university entrance and are seen by some as a dominant feature of education in Chinese contexts (Watkins \& Biggs, 1996). Information gathered through the senses therefore, is likely to predominate rather than the use of imagination and intuition.

There was also a dominance of Introversion over Extroversion in all four studies and in the current study. Huang \& Huang (1992) quote a variety of sources which indicate a Chinese predilection for Introversion. They suggest that Introversion was not only a trait of Chinese living in Taiwan (where their study took place), but also of Chinese living in other parts of the world.

Given that the total number of subjects in the studies being considered above is small (total $n=991)$ and that there are vocational and educational biases in the samples, it would not be advisable to make generalizations about the Chinese population. However, it is interesting to note that there are very high percentages supporting both Introversion and Sensing. Further work needs to be done with larger samples to see if consistent patterns become evident.

\section{Conclusion}

This article has argued in support of clear relationships between personality, second language learning and strategy use and has presented a variety of research evidence supporting such a relationship. The data collected in Hong Kong however, has demonstrated the difficulty in providing direct, statistical evidence with small sample data collection. In terms of conceptual difficulties, regarding the terminology and definition of personality and learning strategies, more needs to be done to refine precisely what is being identified when these terms are used and more recognition given to the overlap in the skills, abilities and predispositions they denote. Research of this sort presents considerable problems in separating the many variables which influence successful language learning attainment. These variables may relate to self-concept and self-confidence (Clement, et al. 1994), gender (Tannen, 1991), and attitude and motivation (Dornyei, 2003). Clearly separating out these factors presents considerable difficulty in data collection and analysis. Future research requires larger samples and more comprehensive measures of personality and learners strategy use (perhaps using more than one of the standard multi-trait models assessments with same students), so that precise statistical evidence can be found that will shed light on the intuitive belief held by teachers and educators of the importance of these issues in learning.

\section{Appendix 1}

\section{The Myers Briggs Type Indicator (MBTI)}

A summary of the MBTI is given below. Costa \& McCrae (1989) report on strong correlations between MBTI and the FFM - these are indicated below each preference description.

Extroversion (E) -Introversion (I). An Extrovert is said to receive energy from outside sources, whereas an Introvert is more concerned with the inner world of ideas and is more likely to be involved with solitary activities. This trait does not just describe whether a person is outgoing or shy, but considers whether a person prefers working alone or feels energized and at home working in a team. (Introversion and Extroversion are identical under FFM).

Sensing (S) - Intuition (N). A Sensing preference relies on gathering information through the five senses, attending to concrete, practical facts. Sensers are less likely to see the 'bigger picture' and more likely to follow a step by step approach. An Intuitive thinker is more likely to be drawn by abstract possibilities, meanings and relationships and will be drawn by the innovative and theoretical. (FFM terminology describes Sensing as Closed and Intuition as Open)

Thinking (T)- Feeling (F). A Thinking person is more likely to prefer decisions made in an impersonal, logical, objective manner. A Feeling person will make decisions based more on personal values, relationships and the feelings of others. Women are more likely to be Feelers. (FFM terminology describes Feeling as Agreeable and Thinking as not prioritizing Agreeableness ) 
Judging (J) - Perceiving (P). This personality preference describes how a person deals with the outside world. The Judger is more likely to look for a planned and controlled life, seeking closure, preferring planning and regulation. The Perceiver deals with the outside world through sensing or intuition, but prefers spontaneity, flexibility, freedom and autonomy and 'playing it by ear'. (FFM terminology describes Judging as high Conscientiousness, and Perceiving as Low Conscientiousness)

\section{References}

Ackerman, P.L. (1999). Traits and knowledge as determinants of learning and individual differences: putting it all together. In P.L. Ackerman \& P. Kyllonen (Eds) Learning and individual differences: process, trait and content determinants. (pps. 437-462). Atlanta: Georgia Institute of Technology.

Ackerman, P.L. (1994). Intelligence, attention and learning: maximal and typical performance. In D.K. Detterman (ed) Current topics in human intelligence: Theories of intelligence. (pp. 1-27) Norwood: Ablex.

Biggs, J.B. (1987).Student approaches to learning and studying. Hawthorn, Victoria: Australia Council for Educational Research.

Blease, T. (1986). Teachers personal constructs and their pupils self images. Educational Studies 12, 255-264.

Blickle, G. (1996). Personality traits, learning strategies and performance. European Journal of Personality 10, 337-352.

Briggs Myers, I.; McCaulley; M.L.; Quenk, N.L. \& Hammer, A.L. (1998). MBTI Manual: a guide to the development and use of the Myers-Briggs Type Indicator. Palo Alto, CA: Consulting Psychologists Press.

Broer, E. \& McCarley, G. (1999).Using and validating the Myers-Briggs Type Indicator in Mainland China. Journal of Psychological Type 51, 5-21.

Busato, V.; Prins, F.;Elshout J. \& Hamaker, C. (2000). Intellectual ability, learning style, achievement motivation, and a academic success of psychology students in higher education. Personality and Individual Differences. 29, 1057-1068.

Cano, J. (1999).The relationship between learning style, academic major and academic performance of college students. Journal of Agricultural Education 41. (1): 30-37.

Carrell, P.L. \& Anderson, N.J. (1994). Styles and strategies in second language acquisition. Paper presented at the TESOL Convention, Baltimore. MD, USA.

Carrell, P.L., Prince M.S, \& Astika, G.G. (1996). Personality types and language learning. Language Learning 46, (1): 75-99.

Cattell, R.B. (1987). Intelligence: its structure, growth and action. New York: Springer.

Chamorro-Premuzic, T. \& Furnham, A. (2003). Personality traits and academic examination performance. European Journal of Personality 17. 237-250.

Chamorro-Premuzic, T. \& Furnham, A. (2005). Personality and social competence Mahwah, New Jersey: Lawrence Erlbaum Associates.

Chan, J.; \& Eysenck, S.B.G. (1981). National differences in personality: Hong Kong and England. Paper presented at the Joint IACP-ICP Asian Regional Meeting, National Taiwan University, Taipei, August, 1981. Cited in Huang and Huang, 1992 op.cit.

Clements, R.; Dornyei, Z. \& Noels, K.A. (1994). Motivation, self-confidence and group cohesion in the foreign language classroom. Language Learning, 44, 417-448.

Costa, P.T. \& McCrae, R.R. (1992). Revised NEO Personality Inventory (NEO-PI-R) and NEO Five Factor Inventory (NEO-FFI): Professional Manual. Odessa, Fl: Psychological Assessment Resources.

Dornyei, Z. (2003). Attitudes, orientations and motivations in language learning: advances in theory, research and applications. Language Learning 53, (1): 3-32.

Ehrman, M. \& Oxford, R. (1990). Adult learning styles and strategies in an intensive training setting. Modern Language Journal 74, (3): 311-327.

Eysenck, H.J. (1975). Manual of the Eysenck Personality Questionnaire. London: Hodder and Stoughton.

Eysenck, H.J. \& Cookson, L. (1969). Personality and Primary school children - ability and achievement. British Journal of Educational Psychology. 39, 109-130.

Gagne F. \& St Pere, F. (2001). When IQ is controlled, does motivation still predict achievement?' Intelligence 30, 71-100. 
Geisler-Brenstein, E. \& Schmeck, R. (1996). The revised inventory of learning processes: a multifaceted perspective on individual differences in learning. In M. Birenbaum and F. Dochy (Eds) Alternative in assessment of achievement, learning processes and prior knowledge: Evaluation in education and human service (pp. 283-317) New York: Kluwer Academic.

Goh, C.C. M. \& Foong, K.P. (1997). Chinese ESL students' learning strategies: a look at frequency, proficiency and gender. Hong Kong Journal of Applied Linguistics 2, (1): 39-51.

Goh, M. \& Moore, C. (1987). Personality and academic achievement in three educational levels. Psychological Reports, 43, 71-79.

Griffith, R. (1991). Personality and second language learning: theory, research and practice. In Sadtono, E. (Ed) Language acquisition and the second/foreign language classroom. Singapore: SEAMEO. .

Harris, V. \& Grenfell, M. (2004).Language learning strategies: a case for cross-cultural collaboration.Language Awareness 13, 2.

Harrison, C. (2002). The National Strategy for English as a Key Stage 3: Roots and Research. Department forEducation and Skills. London: HMSO.

Hassall, S. (1984).An application of "The Good Language Learner" to EFL learners in Bahrain. TESOL France Newsletter. 5, pp.15-23.

Huang, C. \& Huang, C. (1992). Chinese university students on the MBTI. Psychological Testing 39, 285-295.

Jensen A.R. (1980). Uses of sibling data in educational and psychological research. American Educational Research Journal 17, 153-170.

Kiany G.R. (1998). English proficiency and academic achievement in relation to Extroversion: a preliminary study. International Journal of Applied Linguistics 8, (1): 113-129

Klassen, J. (1994). The language learning strategies of freshmen English students in Taiwan: a case study. Unpublished Masters thesis, California State University of Chico.

Lathey, J. (1991). Temperament style as a predictor of academic achievement in early adolescence. Journal of Psychological Type 22, 52-58.

Li, J. \& Qin X. (2006). Language learning styles and learning strategies of tertiary level English learners in China. RELC journal 37.1. 67-89.

Li, J. \& Qin, X. (2003). The relation of learning styles to language learning outcomes: an empirical study. Hong Kong Journal of Applied Linguistics 8, (1): 17-31.

Marton,F. \& Saljo, R. (1976). On qualitative differences in learning 1: outcomes and processes. British Journal of Educational Psychology 46, 4-11.

McDonough, S.H. (1986). Psychology for Language Teachers. London: Unwin Hyman.

Messick, S. (1994). The matter of style: manifestations of personality in cognitive, learning and teaching. Educational Psychologist 29, 121-136.

Neisser, U.; Boodoo, G.; Bouchard, T.; Boykin A.; Brody, N.; Ceci S.; Halpern D.; Loehlin J.; Perloff R.; Sternberg, R.; Boykin A. \& Urbina S. (1996) Intelligence: knowns and unknowns. American Psychologist. 45, 77-101.

O’Malley, J.M.; Chamot, A.U.; Stewner-Manzanares, G.; Kupper, L. \& Russo, R.P.; (1985a). Learning strategies used by beginning and intermediate ESL students. Language Learning 35, 21-46.

O’Malley, J.M. \& Chamot, A.U.; Stewner-Manzanares, G.; Kupper, L. \& Russo, R.P. (1985b). Learner strategy applications with students of English as a second language. TESOL Quarterly 19, 285-96.

Oxford, R.L. (1995). What Every Teacher Should Know. New York: Newbury House.

Oxford, R.L. \& Anderson, N.J. (1995). A cross-cultural view of learning styles. Language Teaching 28, 201-215.

Robinson, D., Gabriel, N. \& Katchan, O. (1994). Personality and individual differences. Individual Differences 16, (1): 143-157.

Sanchez-Marin, M.; Rejano-Infant, E. \& Rodriguez-Troyano, Y. (2001). Personality and academic productivity in the university student. Social Behaviour and Personality 29, 299-305.

Sharp, A. (2005). Individual differences in language learning: the effects of Jungian personality type. International Journal of Learning 11, 633-639.

Singh R. \& Varma S.K. (1995). The effect of academic aspiration and intelligence on scholastic achievement of XI graders. Indian journal of Psychometrics and Education 26, 43-48. 
Skehan, P. (1998). Cognitive approaches to language learning Oxford: Oxford University Press.

Sternberg, R. \& Kaufman, J. (1998). Human abilities. Annual Review of Psychology 49, 479-502.

Tannen, D. (1991). You just don't understand: women and men in conversation. London: Virago.

Watkins, D.A. \& Biggs, J. (eds).(1996). The Chinese Learner. Hong Kong, Comparative Education Research Centre/ Australia Council for Educational Research.

Weiss,L. (1998).The relationship between personality variables and the completion of a doctoral dissertation.Dissertation Abstracts International 48, 2814-2815.

Wiggins, J.S. (1989). Review of Myers - Briggs Type Indicator. In Conoley, J.C. \& Kramer, J.J. (Eds)The Tenth Mental Measurement Yearbook (pp.536-538) Nebraska, Om: Buros Institute of Mental Measurement of the University of Nebraska-Lincoln.

Woodrow, L. (2006). Anxiety and speaking English as second language. RELC Journal 37, (3): 308-328.

Yang, N.D. (1994). An investigation of Taiwanese college students' use of English learning strategies. Research report, National University, Taiwan.

Yao, Y. (1999). Analyses of the MBTI personality types of Chinese female school administrators in Liaoning Province, PRC. Unpublished doctoral dissertation, Mississippi State University. 1993 Cited in Broer and McCarley op.cit.

Zemke, R. (1992). Second thoughts about the MBTI. Training. 29, 5, 43-49.

Table 1. MBTI results (combined traits)

$\begin{array}{llll}\underline{\text { ISTJ }} & \underline{\text { ISFJ }} & \underline{\text { INFJ }} & \underline{\text { INTJ }} \\ \mathrm{N}=14 & \mathrm{~N}=12 & \mathrm{~N}=0 & \mathrm{~N}=3 \\ \underline{\text { ISTP }} & \underline{\text { ISFP }} & \underline{\text { INFP }} & \underline{\text { INTP }} \\ \mathrm{N}=6 & \mathrm{~N}=12 & \mathrm{~N}=7 & \mathrm{~N}=2 \\ \underline{\text { ESTP }} & \underline{\text { ESFP }} & \underline{\text { ENFP }} & \underline{\text { ENTP }} \\ \mathrm{N}=4 & \mathrm{~N}=6 & \mathrm{~N}=8 & \mathrm{~N}=3 \\ \underline{\text { ESTJ }} & \underline{\text { ESFJ }} & \underline{\text { ENFJ }} & \underline{\text { ENTJ }} \\ \mathrm{N}=7 & \mathrm{~N}=4 & \mathrm{~N}=8 & \mathrm{~N}=4\end{array}$

Table 2. MBTI (individual traits)

$\begin{array}{ccccc}\text { E } & 44 \% & \text { S } & 65 \% \\ \text { I } & 56 \% & \text { N } & 35 \% \\ \text { T } & 43 \% & \text { J } & 52 \% \\ \text { F } & 57 \% & & \text { P } & 48 \%\end{array}$




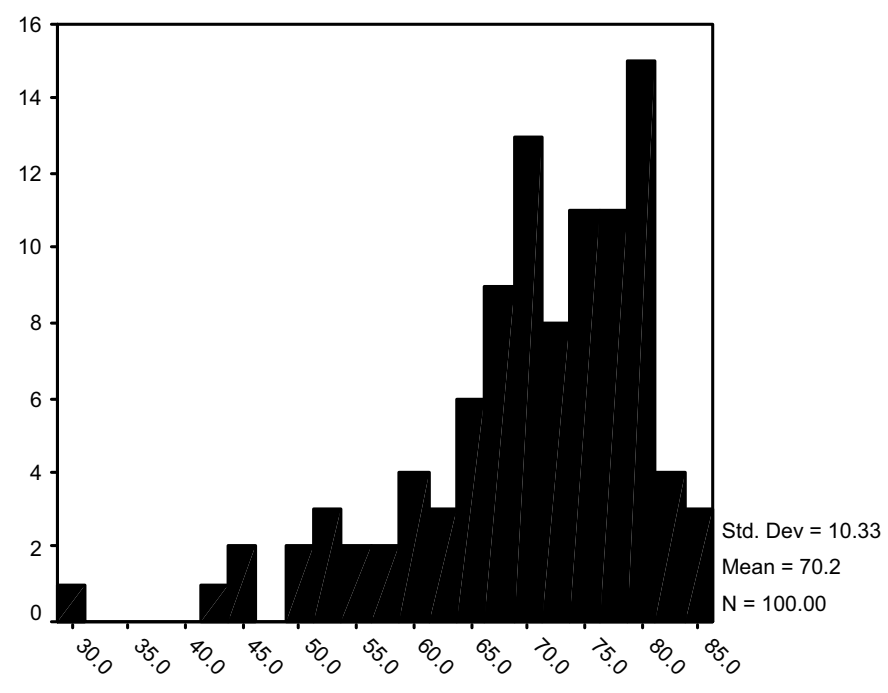

prof. test

Table 3. Language Proficiency Test Results

Table 4. Ranked SILL Results:

$\begin{array}{lll} & \text { Mean } & \\ \text { Compensation } & 3.4 & 0.5 \\ \text { Metacognitive } & 3.3 & 0.5 \\ \text { Cognitive } & 3.3 & 0.6 \\ \text { Social } & 3.1 & 0.8 \\ \text { Affective } & 2.9 & 0.6 \\ \text { Memory } & 2.7 & 0.6\end{array}$

Table 5. MBTI and Proficiency

$\begin{array}{ll}\mathrm{I}(71.50) & \mathrm{E}(68.90) \mathrm{p}=.156 \\ \mathrm{~S}(70.22) & \mathrm{N}(70.65) \mathrm{p}=.844 \\ \mathrm{~F}(70.16) & \mathrm{T}(70.64) \mathrm{p}=.711 \\ \mathrm{P}(70.38) & \mathrm{J}(70.37) \mathrm{p}=.866\end{array}$

(Bracketed number is the proficiency score as a percentage) 